\title{
Persepsi Warga Jakarta Terhadap Pelayanan Publik Dengan Metode IPA Dan CSI
}

\author{
Aloysius Rangga Aditya Nalendra ${ }^{1}$, Bryan Givan $^{2}$, Imelda Sari ${ }^{3}$ \\ ${ }^{12}$ Universitas Bina Sarana Informatika,aloysius2206@bsi.ac.id \\ ${ }^{2}$ Universitas Bina Sarana Informatika, bryan.bgv@bsi.ac.id \\ ${ }^{3}$ Universitas Bina Sarana Informatika, imelda.isx@bsi.ac.id
}

\begin{abstract}
ABSTRAK
Penelitian ini meneliti pelayanan yang dilakukan di pusat pelayanan publik tingkat pertama yakni kelurahan. Penelitian ini bertujuan untuk melihat persepsi warga DKI Jakarta terhadap layanan publik di era Anies Baswedan. Penelitian ini menggunakan 1000 responden dengan teknik insidental. Penelitian ini meneliti bentuk layanan di kelurahan yang tersebar di lima wilayah DKI Jakarta yakni Jakarta Pusat, Jakarta Timur, Jakarta Barat, Jakarta Utara dan Jakarta Selatan dengan metode pengukuran menggunakan metode IPA dan CSI. Hasil dari penelitian ini adalah secara umum warga DKI Jakarta Puas dan persepsi terhadap layanan publik yang diterima warga bernilai positif dengan ditunjukan nilai CSI sebesar 66,35 dan diagram kartesius di dalam bidang B yang artinya bahwa layanan yang diberikan telah baik dan patut dipertahankan. Persepsi warga DKI Jakarta terhadap pelayanan publik di kelurahan pada era Gubernur Anies Baswedan positif. Hal ini ditandai dengan nilai secara global baik CSI maupun IPA yang memberikan nilai positif yang dapat diintrepetasikan bahwa masyarakat DKI Jakarta pada umumnya merasa puas terhadap pelayanan yang diberikan kepada warga lewat pelayanan publik di dalam kelurahan. Hanya dua wilayah DKI Jakarta yang perlu untuk meningkatkan pelayanan agar warga DKI Jakarta dapat puas yakni kelurahan-kelurahan yang berada di wilayah Jakarta Barat dan Jakarta Timur.

Kata Kunci: Importance-Performance Analysis, Customer Satisfaction Index
\end{abstract}

\begin{abstract}
This study examines services performed at the first-level public service center, the kelurahan. This study aims to look at the perception of DKI Jakarta citizens towards public service in the Anis Baswedan era. This study used 1000 respondents with incidental techniques and sampling using the cluster sample method. This study examines service layouts in villages that are spread over 5 regions of DKI Jakarta, namely Central, East, North West and South Jakarta with measurement methods using the Natural Sciences and CSI methods. The results of this study are in general the citizens of DKI Jakarta are satisfied and the perception of public services received by citizens is positive with a CSI value of 66.35 and a Cartesian diagram in field $B$ which means that the services provided are good and should be maintained. The perception of DKI Jakarta residents towards public services in urban villages during the era of Governor Anies Baswedan was positive. This is the global value of both CSI and IPA which has a positive impact which can be interpreted that the people of DKI Jakarta generally feel satisfied with the services provided to citizens through public services in the kelurahan. Only two areas of DKI Jakarta need to improve services so that the citizens of DKI Jakarta can be satisfied, namely the villages located in West Jakarta and East Jakarta.
\end{abstract}

Keywords: Importance-Performance Analysis, Customer Satisfaction Index

Naskah diterima: 27-08-2020, direvisi: 01-07-2020, diterbitkan: 01-09-2020

PENDAHULUAN

Sebagai ibu kota Negara Indonesia, Jakarta adalah pusat kegiatan bisnis sekaligus pusat kegiatan pemerintahan, maka Jakarta menjadi daerah tujuan masyarakat untuk tinggal dan menjadi destinasi masyarakat 
mengadu nasib mencari peruntungan untuk bekerja di Jakarta. Sebagai ibu kota negara serta daerah tujuan masyarakat untuk mencari mata pencarian, Jakarta di era Gubernur Anies Baswedan, dituntut memiliki pelayanan publik yang mumpuni yang dapat memuaskan masyarakat. Pelayanan yang baik, membuat warga merasa terlayani dengan baik (Nalendra et al., 2018) sehingga akan menciptakan kemajuan untuk kotanya dan akan membuat bahagia warganya.

Penelitian ini meneliti pelayanan yang dilakukan di pusat pelayanan publik tingkat pertama yakni kelurahan. Kelurahan merupakan ujung tombak dari pemerintahan daerah karena langsung berhadapan dengan masyarakat secara langsung. Selain itu, citra birokrasi pemerintah daerah DKI Jakarta ditentukan oleh kinerja organisasi tersebut. Hal ini senada dengan penelitian yang dilakukan oleh Marini, mengungkapkan bahwa kelurahan sebagai suatu sistem pemerintahan Indonesia memiliki peranan penting dalam pelayanan masyarakat dan penentu citra birokrasi pemerintah (Rindengan, 2016).

Penelitian ini menggunakan metode IPA (Importance Performance Analysis) untuk menunjukkan atribut produk atau jasa yang perlu ditingkatkan ataupun dikurangi untuk menjaga kepuasan konsumen dalam hal ini adalah kepuasan warga jakarta (Anggraini et al., 2015). Selain itu, dalam penelitian ini juga menggunakan metode Customer Satisfaction Index (CSI) untuk mengetahui tingkat kepuasan konsumen. Metode ini memiliki beberapa keunggulan antara lain efisiensi artinya bahwa tidak hanya indeks kepuasan tetapi sekaligus memperoleh informasi yang berhubungan dengan dimensi atau atribut yang perlu diperbaiki, mudah digunakan dan sederhana serta menggunakan skala yang memiliki sensitivitas dan reliabilitas cukup tinggi (Anggraini et al., 2015). Secara umum tujuan penelitian ini harapannya dapat memberikan sumbangsih hasil riset kepada institusi dan penelitian yang dapat berkelanjutan bagi mahasiswa maupun peneliti lain yakni dengan cara publisitas di dalam jurnal nasional. Adapun tujuan khusus dalam penelitian ini adalah dengan penelitian ini diharapkan dapat menjadi bahan literatur serta feedback kepada pemerintah daerah DKI Jakarta berkaitan dengan persepsi warga terhadap kepuasan pelayanan publik Kota Jakarta di era Gubernur Anies Baswedan. Dengan penelitian ini, pemerintah daerah DKI Jakarta dapat mengetahui tingkat kepuasan warga terhadap pelayanan publik yang telah diberikan sehingga dapat memperbaiki layanan publik yang belum sesuai. Urgensi dalam penelitian ini adalah dengan melakukan penelitian ini, peneliti hendak mengemukakan mengenai persepsi warga Jakarta terhadap kepuasan pelayanan publik DKI Jakarta di era Gubernur Anies Baswedan. Dengan kata lain bahwa tujuan penelitian ini adalah memberikan feed back berupa data persepsi masyarakat terhadap kepuasaan pelayanan publik di era Gubernur Anies Baswedan kepada pihak pemerintah daerah Jakarta. Peneliti melakukan observasi sebagai tahapan awal dalam penelitian. Adapun hasil observasi terungkap bahwa masyarakat memiliki harapan besar terhadap pelayanan publik di tingkat kelurahan yang di lakukan di era Gubernur Anies Baswedan dapat dilakukan dengan optimal serta dapat melayani masyarakat dengan baik. Harapan besar tersebut melahirkan persepsi publik mengenai kinerja pelayanan publik di tingkat kelurahan yang diukur menggunakan metode IPA dan CSI. Berangkat dari hasil observasi tersebut maka peneliti melakukan identifikasi masalah yang dapat dirumuskan menjadi rumusan masalah dalam penelitian yakni bagaimana persepsi warga Jakarta terhadap pelayanan publik di era Gubernur Anies Baswedan. Adapun penulis memberikan batasan penelitian yakni penelitian ini hanya menitikberatkan kepada pelayanan masyarakat yang berada di kelurahan dalam wilayah DKI Jakarta yang peneliti bagi menjadi beberapa area. Keterbatasan penelitian ini, peneliti tidak melibatkan area kepualuan seribu dikarenakan keterbatasan penelitian. Sedangkan untuk batasan masalah, peneliti membatasi ruang lingkup pembahasan hanya kepada persepsi warga DKI berdasarkan metode IPA dan CSI berdasarkan arahan PERMENPAN NO 14 tahun 2017. 


\section{KAJIAN LITERATUR}

\section{A. PERMENPAN NO 14 tahun 2017}

Untuk melaksanakan pelayanan publik yang baik perlu ada kontrol dan evaluasi sehingga pemerintah menerbitkan Permenpan no 14 tahun 2017.

Dalam Permenpan No. 14 Tahun 2017 unsur-unsur yang menjadi fokus dalam pelaksanaan Survei Kepuasan Masyarakat terdiri dari 9 unsur untuk menjadi indikator kualitas pelayanan yang terdiri dari:

1. Persyaratan adalah syarat yang harus dipenuhi dalam pengurusan suatu jenis pelayanan, baik persyaratan teknis maupun administratif;

2. Sistem, mekanisme dan prosedur adalah tata cara pelayanan yang dilakukan bagi pemberi dan penerima pelayanan termasuk pengaduan;

3. Waktu penyelesaian adalah jangka waktu yang diperlukan untuk menyelesaikan seluruh proses pelayanan dari setiap jenis pelayanan;

4. Biaya/Tarif adalah ongkos yang dikenakan kepada penerima layanan dalam mengurus dan atau memperoleh pelayanan dari penyelenggara yang besarnya ditetapkan berdasarkan kesepakatan antara penyelenggara dan masyarakat;

5. Produk Spesifikasi Jenis Pelayanan adalah hasil pelayanan yang diberikan dan diterima sesuai dengan ketentuan yang ditetapkan. Produk pelayanan ini merupakan hasil dari setiap spesifikasi jenis pelayanan;

6. Kompetensi Pelaksana adalah kemampuan yang harus dimiliki oleh pelaksana meliputi pengetahuan keahlian keterampilan dan pengalaman;

7. Perilaku Pelaksana adalah sikap petugas memberikan pelayanan;

8. Penanganan pengaduan, saran dan masukan adalah tata cara pelaksanaan penanganan pengaduan dan tindak lanjut;

9. Sarana adalah segala sesuatu yang dapat dipakai sebagai alat dalam mencapai maksud dan tujuan. Prasarana adalah segala sesuatu yang merupakan penunjang utama terselenggaranya suatu proses (usaha, pembangunan, proyek). Sarana yang digunakan untuk benda yang bergerak (komputer, mesin) dan prasarana untuk benda yang tidak bergerak (gedung) (Kemenpan, 2017).

\section{B. PERSEPSI}

Persepsi merupakan salah satu aspek psikologis yang penting bagi manusia dalam merespon kehadiran berbagai aspek dan gejala di sekitarnya. Dalam persepsi manusia terdapat perbedaan sudut pandang di penginderaan, ada yang mempersepsikan sesuatu itu baik (positif) maupun persepsi buruk (negatif) yang akan mempengaruhi tindakan manusia sehari-hari. Dengan kata lain bahwa persepsi adalah suatu proses mengolah pengetahuan yang telah dimiliki untuk memperoleh dan menginterpretasi stimulus yang diterima oleh sistem alat indra manusia (Anggraini et al., 2015). Maka, pada dasarnya persepsi merupakan hubungan antara manusia dengan lingkungannya, serta bagaimana manusia menggambarkan atau menyampaikan stimulus yang ada di lingkungannya dengan menggunakan pengetahuan yang dimilikinya, kemudian memproses hasil pengindraannya itu, sehingga muncullah makna mengenai objek tersebut (baik atau buruk) (Sastika, 2018). Warga Jakarta mempersepsikan Jakarta sebagai kota besar dengan segala fasilitas pendukung yang prima. Sebagai kota besar, Jakarta dituntut dapat memberikan pelayanan yang prima bagi warganya (Kusumaningrum \& Asfirotun, 2013). Dengan persepsi demikian, maka pelayanan publik seperti pembuatan akta lahir, KTP, kepengurusan izin dan lain lain haruslah dapat diberikan dengan baik sehingga akan membuat maju kotanya dan bahagia warganya. Penelitian ini menitikberatkan kepada persepsi warga Jakarta mengenai pelayanan publik yang diberikan oleh pemerintah DKI Jakarta.

\section{IPA (Importance Performance Analysis dan CSI (Consumer Satisfaction Index)}

Customer satisfaction indeks (CSI) atau yang lebih dikenal dengan indeks kepuasan konsumen merupakan metode yang menggunakan indeks untuk mengukur 
tingkat kepuasan konsumen berdasarkan atribut-atribut tertentu. Atribut yang diukur dapat berbeda untuk masing-masing perusahaan.

Ada enam langkah penentuan CSI yakni:

1. Menentukan Mean Importance (MIS);

2. Menetukan Mean Satisfaction Score (MSS);

3. Menentukan Weight Factors (WF);

4. Menentukan Weight Score (WS);

5. Menentukan Weight Total (WT);

6. Menentukan CSI.

Sedangkan IPA adalah ImportancePerformance Analysis (IPA) digunakan sebagai teknik analisis data untuk mengukur kualitas pelayanan serta untuk melihat apakah ada kesenjangan (gap) antara kualitas pelayanan yang diberikan oleh pemerintah DKI Jakarta era Gubernur Anies Baswedan dengan yang diharapkan oleh masyarakat. Berdasarkan skor rata-rata tingkat persepsi pelayanan yang merupakan hasil dari kinerja pemerintah serta skor rata-rata harapan yang dapat diaplikasikan ke dalam diagaram Kartesius (Kotler, 2012) yang terbagi dalam empat wilayah atau kuadran, yaitu prioritas utama (A), pertahankan prestasi (B),

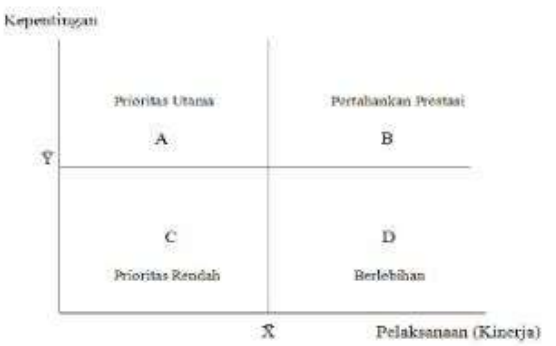

Sumber : Kotler, '2UI'2

Gambar I. Diagram Kartesius IPA

Dari uraian teori maka penulis mengembangkan model penelitian yang dapat dilihat dalam kerangka penelitian sebagai berikut:

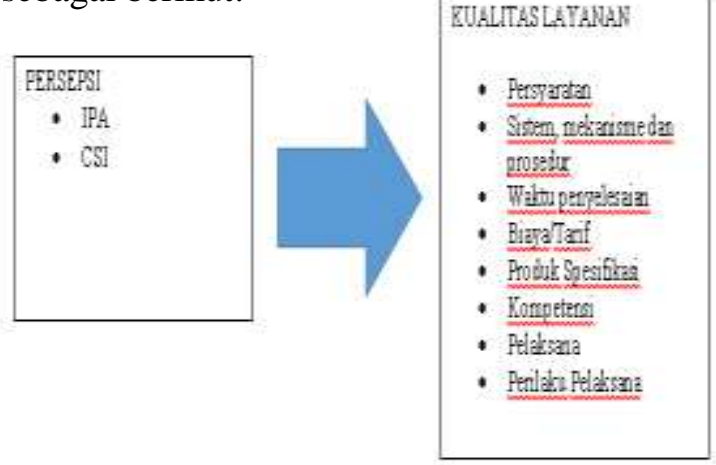

Sumber: (Nalendra et al., 2018)

Gambar II. Kerangka Berpikir
Dari kerangka penelitian ini dapat dijelaskan bahwa persepi warga Jakarta dapat diukur dengan Metode IPA dan CSI. Penggunaan metode IPA dan CSI bertujuan untuk mengukur persepsi warga terhadap kualitas pelayanan yang meliputi sembilan aspek yakni Persyaratan, Sistem, Mekanisme dan Prosedur, Waktu Penyelesaian, Biaya/Tarif, Produk Spesifikasi, Kompetensi, Pelaksana, Perilaku Pelaksana. Sembilan aspek ini berguna sebagai indikator pengukuran kualitas pelayanan yang diberikan di dalam kelurahan dalam era Anies Baswedan.

\section{METODE PENELITIAN}

\section{A. Alat dan Bahan}

Penelitian kuantitatif ini menggunakan metode survei. Untuk mendapatkan sampel, peneliti menggunakan teknik insidental sebagai teknik pengambilan sampel. Teknik sampling insidental adalah teknik penentuan sampel berdasarkan kebetulan, yaitu siapa saja yang secara kebetulan atau insidental bertemu dengan peneliti dapat digunakan sebagai sampel, bila dipandang orang yang kebetulan ditemui itu cocok sebagai sumber data (Sugiyono, 2015). Dari paparan tersebut maka dalam penelitian ini menggunakan teknik insidental untuk penentuan sampel yakni setiap pengguna layanan publik di kelurahan yang berada di kelima wilayah DKI Jakarta dan didapat sejumlah 1000 orang yang mewakili setiap wilayah Jakarta dengan rincian sebagai berikut:

1. Responden yang ditemui di kelurahan dalam wilayah Jakarta Pusat sejumlah 239 responden;

2. Responden yang ditemui di kelurahan dalam wilayah Jakarta Selatan sejumlah 164 responden;

3. Responden yang ditemui di kelurahan dalam wilayah Jakarta Utara sejumlah 201 responden;

4. Responden yang ditemui di kelurahan dalam wilayah Jakarta Barat sejumlah 186 responden;

5. Responden yang ditemui di kelurahan dalam wilayah Jakarta Timur sejumlah 210 responden;

Metode analisa data yang digunakan adalah metode IPA dan CSI yang berfungsi mengukur tingkat kepuasan pelayanan dan 
persepsi warga Jakarta di era Gubernur Anies Baswedan.

Adapun tahapan dalam penelitian ini terbagi menjadi lima tahapan yakni:

1. Persiapan Penelitian

Peneliti melakukan survey dan observasi pendahuluan guna memetakan permasalahan. Setelah melakukan pemetaan permasalahan langkah selanjutnya yakni melakukan identifikasi masalah dan merumuskan masalah sehingga dihasilkan judul dan proposal penelitian;

2. Persiapan Pengambilan Data

Peneliti mempersiapkan diri dengan studi literatur guna mendukung penelitian, langkah selanjutnya yakni penentuan metode penelitian, menentukan jumlah populasi dan sampel dan penggunaan metode yang sesuai. Setelah itu peneliti mengambil data dengan metode insidental dan dicatat secara sistematis;

3. Pengolahan Data

Pada langkah ini peneliti melakukan uji validitas dan reliabilitas serta penggunaan metode IPA dan CSI untuk menjawab rumusan masalah yang telah dirumuskan;

4. Analisa Hasil Penelitian

Pada langkah ini, peneliti melakukan analisa data dengan pendekatan metode IPA dan CSI sehingga mendapatkan temuan dan mengintrepetasikan hasil. Peneliti dapat menyusun laporan awal dan akhir sebagai bentuk pertanggungjawaban peneliti;

5. Diseminasi Hasil Penelitian

Pada langkah akhir ini, peneliti mempublikasikan hasil temuan sebagai luaran wajib di jurnal nasional Ecodemica.

\section{B. Metode Penelitian}

Untuk menganalisa data maka diperlukan sebuah uji instrument. Peneliti melakukan uji validitas dan uji reliabilitas terhadap instrument penelitian yakni berupa kuesioner yang bertujuan agar mendapatkan data yang valid. Sedangkan dalam menganalisa data peneliti menggunakan metode IPA dan CSI guna menganalisa persepsi warga DKI Jakarta terhadap pelayanan Publik di era Gubernur Anies Baswedan.

\section{PEMBAHASAN}

1. Deskripsi Responden

Dalam penelitian ini menggunakan 1000 sampel responden yang dapat dideskripsikan sebagai berikut:

Berdasarkan sebaran umur, responden yang ditemukan maka dapat dilihat sebaran umur sebagai berikut:
1. 17-25 tahun
$=256$ orang
2. 26-45 tahun $=476$ orang
3. diatas 46 tahun $=268$ orang

Selain itu, dari sebaran data yang ada dapat ditemukan sebaran jenis kelamin sebagai berikut:

1. Laki-laki $=554$ orang

2. Perempuan $=446$ orang

Dari sebaran tingkat pendidikan, berdasarkan data yang ada didapat informasi sebagai berikut:
1. $\mathrm{SD}=23$ orang
2. $\mathrm{SMP}=66$ orang
3. $\mathrm{SMA}=530$ orang
4. $\mathrm{D} 3=157$ orang
5. $\mathrm{S} 1=170$ orang
6. $\mathrm{S} 2=50$ orang
7. $\mathrm{S} 3=4$ orang

Dari data yang ada maka disimpulkan bahwa adanya heterogenitas data yang didapatkan dikarenakan keragaman responden yang ditemui.

\section{Uji Validitas dan Reliabilitas}

Padas sub bab ini, peneliti melakukan uji instrument berupa kuisoner yang bertujuan untuk mendapatkan data yang valid untuk dapat dianalisa. Kuesioner yang digunakan mengacu kepada rumusan PERMENPAN NO 14 tahun 2017. Adapun hasil perhitungan disajikan dalam tabel dibawah ini. 
Tabel 1

Hasil Uji Validitas

\begin{tabular}{|c|c|c|c|}
\hline $\begin{array}{l}\text { No } \\
\text { Item }\end{array}$ & $\begin{array}{l}\mathrm{R} \\
\text { Hitung }\end{array}$ & $\begin{array}{l}\text { Rtabel 5\% } \\
(\mathrm{N}=30)\end{array}$ & Keterangan \\
\hline 1 & 0.785 & 0.361 & VALID \\
\hline 2 & 0.788 & 0.361 & VALID \\
\hline 3 & 0.801 & 0.361 & VALID \\
\hline 4 & 0.616 & 0.361 & VALID \\
\hline 5 & 0.829 & 0.361 & VALID \\
\hline 6 & 0.817 & 0.361 & VALID \\
\hline 7 & 0.743 & 0.361 & VALID \\
\hline 8 & 0.573 & 0.361 & VALID \\
\hline 9 & 0.822 & 0.361 & VALID \\
\hline 10 & 0.821 & 0.361 & VALID \\
\hline 11 & 0.811 & 0.361 & VALID \\
\hline 12 & 0.872 & 0.361 & VALID \\
\hline 13 & 0.602 & 0.361 & VALID \\
\hline 14 & 0.842 & 0.361 & VALID \\
\hline 15 & 0.801 & 0.361 & VALID \\
\hline 16 & 0.722 & 0.361 & VALID \\
\hline 17 & 0.615 & 0.361 & VALID \\
\hline 18 & 0.792 & 0.361 & VALID \\
\hline
\end{tabular}

Sumber: Data Diolah, 2020

Dari tabel I dapat disimpulkan bahwa ke delapan belas item pertanyaan yang ada telah diuji validitasnya dan dihasilkan kesimpulan bahwa kedelapan belas item yang ada valid.

Langkah selanjutnya peneliti melakukan uji reliabilitas didapat hasil seperti dalam table dibawah ini

Tabel 2

Hasil Data Reliabilitas

\begin{tabular}{|c|c|c|}
\hline Rhitung & $\begin{array}{c}\text { Rtabel 5\% } \\
(\mathrm{N}=30)\end{array}$ & Keterangan \\
\hline 0.957 & 0.361 & RELIABEL \\
\hline
\end{tabular}

Sumber: Data Diolah, 2020

Dari tabel II didapat kesimpulan bahwa semua item pertanyaan dalam kuesioner yang digunakan adalah reliabel.

Setelah melakukan uji intrumen dan didapat hasil bahwa instrumen penelitian berupa kuesioner telah valid dan reliabel untuk digunakan maka peneliti melakukan analisa data menggunakan metode IPA dan CSI untuk menggambarkan persepsi warga terhadap layanan publik di DKI Jakarta era Anies Baswedan.

\section{Analisa Data}

Dalam penelitian ini peneliti menyajikan data secara gambaran umum dan memberikan gambaran setiap wilayah. Metode yang digunakana adalah metode IPA dan CSI.

\section{Metode IPA}

Dari hasil perhitungan secara umum maka didapat hasil IPA dengan menghitung tingkat kesesuaian sebagai berikut:

$$
\mathrm{TK}=\frac{\mathrm{X} 1}{\mathrm{Y} 1} \times 100 \%
$$

Maka di dapat hasil sebagai berikut

Tabel 3

Hasil Perhitungan Tingkat Kesesuaian

\begin{tabular}{|c|c|c|}
\hline \multicolumn{2}{|c|}{ Rumus } & Hasil \\
\hline TK 1 = 3342/3630 & $\times 100 \%$ & 92,06612 \\
\hline TK 2 = 3355/3625 & $\times 100 \%$ & 92,55172 \\
\hline TK 3 = 3088/3571 & $\times 100 \%$ & 86,47438 \\
\hline TK 4 =3596/3742 & $\times 100 \%$ & 96,09834 \\
\hline TK 5 = 3320/3585 & $\times 100 \%$ & 92,60809 \\
\hline TK 6 = 3334/3601 & $\times 100 \%$ & 92,58539 \\
\hline TK 7 = 3326/3639 & $\times 100 \%$ & 91,39874 \\
\hline TK 8 = 3344/3589 & $\times 100 \%$ & 93,17359 \\
\hline TK 9 = 3139/3587 & $\times 100 \%$ & 87,51045 \\
\hline
\end{tabular}

Sumber: Data Diolah

$$
\text { TK total }=\frac{\Sigma X 1}{\Sigma Y 1} \times 100 \%
$$

Untuk tingkat kesesuaian total didapat

$$
\begin{aligned}
& \Sigma \mathrm{X} 1=29844 \\
& \Sigma \mathrm{Y} 1=32569 \\
& \mathrm{TK} \text { total }=\frac{29844}{32569} \times 100 \%
\end{aligned}
$$

TK total $=91 \%$

Sedangkan untuk rerata di dapat hasil perhitungan sebagai berikut:

Skor Rata-Rata Tingkat X dan Y 


$\begin{array}{ll}\text { Skor Rata-Rata } & =\frac{\text { Xrata-rata }}{\mathrm{k}} \\ \mathrm{X} & =\frac{29.844}{18} \\ & =1.65 \\ \mathrm{Y} & =\frac{32.569}{18} \\ & =1.80\end{array}$

Dari hasil perhitungan tersebut dapat digambarkan diagram kartesius sebagai berikut:

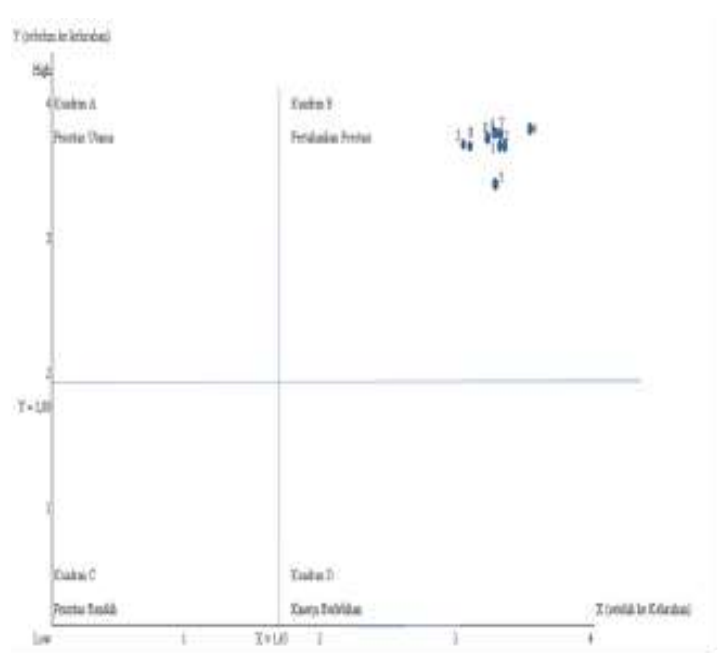

Sumber: Data Diolah

Gambar II Diagram Kartesius Seluruh Area Kelurahan di Jakarta

Dari hasil perhitungan tersebut dapat disimpulkan bahwa pelayanan yang diberikan berada pada Kuadran B ini menunjukkan unsur atau jasa pokok pelayanan telah berhasil dilaksanakan. Pada Gambar II Diagram kartesius semua atribut berada di kuadran B yakni yang meliputi persyaratan, sistem, mekanisme dan prosedur, waktu penyelesaian, biaya/tarif, produk spesifikasi jenis pelayanan, kompetensi pelaksana, perilaku pelaksana, penanganan pengaduan, saran dan masukan, sarana dan prasarana puas dengan pelayanan publik era Anies Baswedan. Untuk itu wajib dipertahankan prestasi kinerja tersebut. Hal ini mencerminkan adanya persepsi warga yang positif yakni layanan yang diberikan sangat memuaskan. Dengan kata lain secara garis besar layanan yang diberikan kepada warga telah memberikan kepuasan kepada warga.
Untuk menyajikan data secara detail peneliti membagi perhitungan ke dalam setiap wilayah Jakarta.

\section{Jakarta Pusat}

Di dalam kelurahan yang berada di area wilayah Jakarta Pusat di dapat hasil sebagai berikut :

$\begin{array}{lrr}\text { TK total }= & \frac{\Sigma \mathrm{X} 1}{\Sigma \mathrm{Y} 1} & \times 100 \% \\ \Sigma \mathrm{X} 1= & 7384 & \\ \Sigma \mathrm{Y} 1= & 7230 \\ \mathrm{TK} \text { total }= & \frac{7384}{7230} \times 100 \% \\ \text { TK total }= & 102 \% & \end{array}$

Skor Rata-Rata Tingkat X dan Y

$\begin{array}{ccc}\text { Skor Rata-Rata } & =\frac{\mathrm{X} \text { rata-rata }}{\mathrm{k}} \\ \mathrm{X} & =\frac{30.90}{18} \\ \text { titik potong X } & = & 1.72 \\ \mathrm{Y} & = & 30.25 \\ \text { titik potong } \mathrm{Y} & = & 18\end{array}$

Maka dari perhitungan tersebut dapat digambarkan diagaram kartesius sebagai berikut:

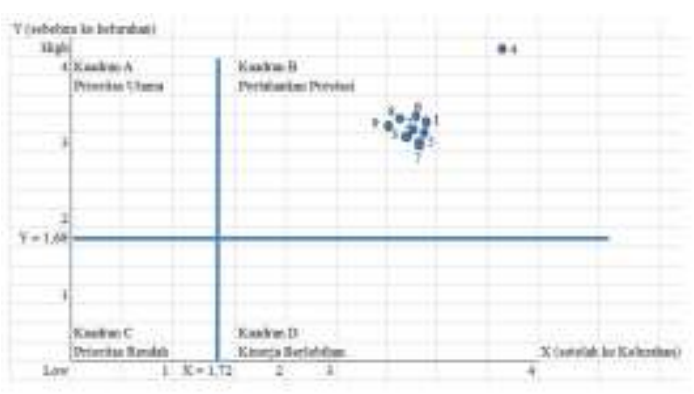

Sumber: Data Diolah

Gambar IV Diagram Kartesius Area Kelurahan di Jakarta Pusat

Dari pemaparan hasil Diagram Kartesius pada gambar IV dapat diinterpretasikan bahwa pelayanan di kelurahan yang berada 
di area Jakarta Pusat memberikan kepuasan kepada warga yang berada di kelurahan Jakarta Pusat. Dengan kata lain bahwa pelayanan yang diberikan berada pada Kuadran B ini menunjukan unsur atau jasa pokok pelayanan telah berhasil dilaksanakan. Pada Gambar IV Diagram Kartesius semua atribut berada di kuadran B yakni yang meliputi persyaratan, sistem, mekanisme dan prosedur, waktu penyelesaian, biaya/tarif, produk spesifikasi jenis pelayanan, kompetensi pelaksana, perilaku pelaksana, penanganan pengaduan, saran dan masukan, sarana dan prasarana puas dengan pelayanan publik era Anies Baswedan. Untuk itu wajib dipertahankan prestasi kinerja tersebut. Hal ini mencerminkan adanya persepsi warga yang positif yakni dikarenakan adanya layanan yang diberikan sangat memuaskan.

\section{Jakarta Barat}

Di dalam kelurahan yang berada di area wilayah Jakarta Barat di dapat hasil sebagai berikut:

Perhitungan Tingkat Kesesuaian Total Antara X dengan Y

$\begin{array}{ll}\text { TK total }= & \frac{\Sigma \mathrm{X} 1}{\Sigma \mathrm{Y} 1} \times 100 \% \\ \Sigma \mathrm{X} 1= & 4671 \\ \Sigma \mathrm{Y} 1= & 6333 \\ \mathrm{TK} \text { total }= & \frac{4671}{6333} \times 100 \% \\ \text { TK total }= & 74 \%\end{array}$

Skor Rata-Rata Tingkat X dan Y

Skor Rata-Rata $\quad=\frac{\mathrm{X} \text { rata-rata }}{\mathrm{k}}$

$\mathrm{X}$

$=\frac{25.11}{18}$

Titik Potong X

$=$

1.40

$\mathrm{Y}$

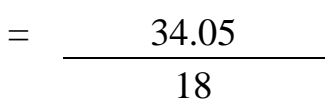

Titik Potong Y

$=$

Maka dari perhitungan tersebut dapat digambarkan diagaram kartesius sebagai berikut:

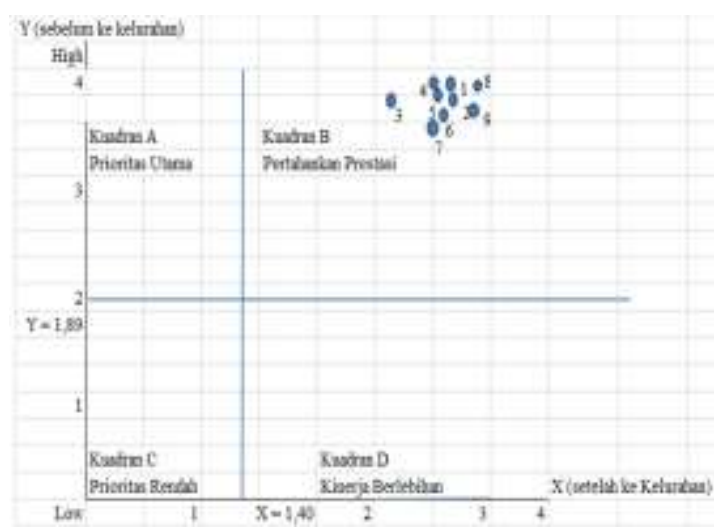

Sumber: Data Diolah

Gambar V Diagram Kartesius Area Kelurahan di Jakarta Barat

Dari diagram kartesius pada gambar V dapat diinterpretasikan bahwa pada gambar kartesius semua atribut berada di kuadran B yakni meliputi persyaratan, sistem, mekanisme dan prosedur, waktu penyelesaian, biaya/tarif, produk spesifikasi jenis pelayanan, kompetensi pelaksana, perilaku pelaksana, penanganan pengaduan, saran dan masukan, sarana dan prasarana puas dengan pelayanan publik era Anies Baswedan, untuk itu wajib dipertahankan. Dengan kata lain bahwa layanan masyarakat dipersepsikan positif, disebabkan kepuasan masyarakat terhadap layanan yang diberikan. Hal ini mengindikasikan bahwa kinerja pegawai kelurahan harus dipertahankan agar persepsi warga terhadap pelayanan publik yang diberikan tetap dan tidak mengalami penurunan.

\section{Jakarta Timur}

Di dalam kelurahan yang berada di area wilayah Jakarta Timur didapat hasil sebagai berikut 
Perhitungan Tingkat Kesesuaian Total Antara X dengan $\mathrm{Y}$

$\begin{array}{lll}\text { TK total } & = & \frac{\Sigma X 1}{\Sigma Y 1} \times 100 \% \\ \Sigma X 1 & = & 6110 \\ \Sigma \mathrm{Y} 1 & = & 7079 \\ \text { TK total } & = & \frac{6110}{7079} \times 100 \%\end{array}$

TK total $=86 \%$

Skor Rata-Rata Tingkat X dan Y

Skor Rata-Rata $\quad=\frac{\mathrm{X} \text { rata-rata }}{\mathrm{k}}$

$\mathrm{X} \quad=\frac{29.10}{18}$

Titik Potong $\mathrm{X}=1.62$

Skor Rata-Rata Tingkat X dan Y

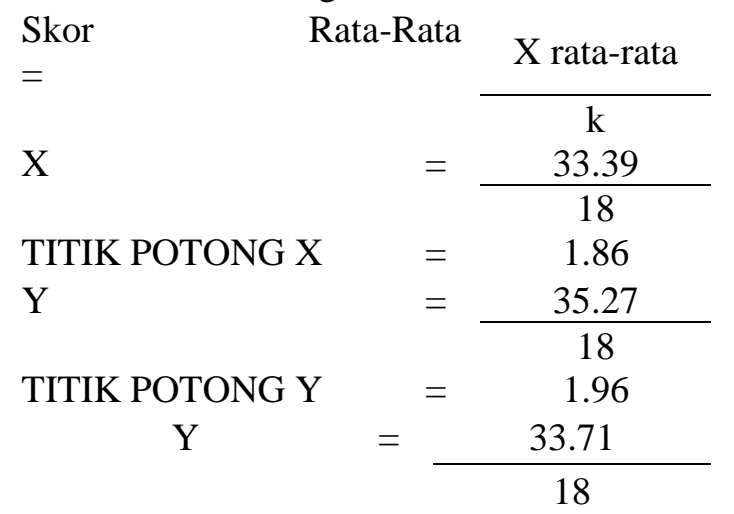

Titik Potong Y $=1.87$

Maka dari perhitungan tersebut dapat digambarkan diagram kartesius sebagai berikut:

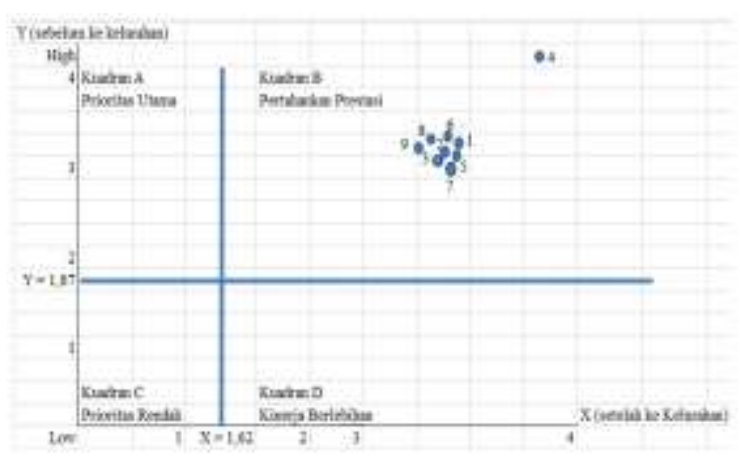

Sumber: Data Diolah

Gambar VI Diagram Kartesius Area Kelurahan di Jakarta Timur
Dari perhitungan dan gambar VI yakni diagram kartisius didapat hasil yakni bahwa pelayanan yang diberikan berada pada Kuadran B ini menunjukan unsur atau jasa pokok pelayanan telah berhasil dilaksanakan. Pada gambar kartesius semua atribut berada di kuadran B yakni yang meliputi persyaratan, sistem, mekanisme dan prosedur, waktu penyelesaian, biaya/tarif, produk spesifikasi jenis pelayanan, kompetensi pelaksana, perilaku pelaksana, penanganan pengaduan, saran dan masukan, sarana dan prasarana puas dengan pelayanan publik era Anies Baswedan. Untuk itu wajib dipertahankan prestasi kinerja tersebut.

\section{Jakarta Utara}

Di dalam kelurahan yang berada di area wilayah Jakarta Utara di dapat hasil sebagai berikut :

Perhitungan Tingkat Kesesuaian Total Antara X dengan Y

$\begin{array}{lll}\text { TK total } & =\frac{\Sigma \mathrm{X} 1}{\Sigma \mathrm{Y} 1} \times 100 \% \\ \Sigma \mathrm{X} 1 & = & 6712 \\ \Sigma \mathrm{Y} 1 & = & 7090 \\ \text { TK total } & = & \frac{6712}{7090} \times 100 \% \\ & & \\ \text { TK total }= & & 95 \%\end{array}$

Maka dari perhitungan tersebut dapat digambarkan diagaram kartesius sebagai berikut:

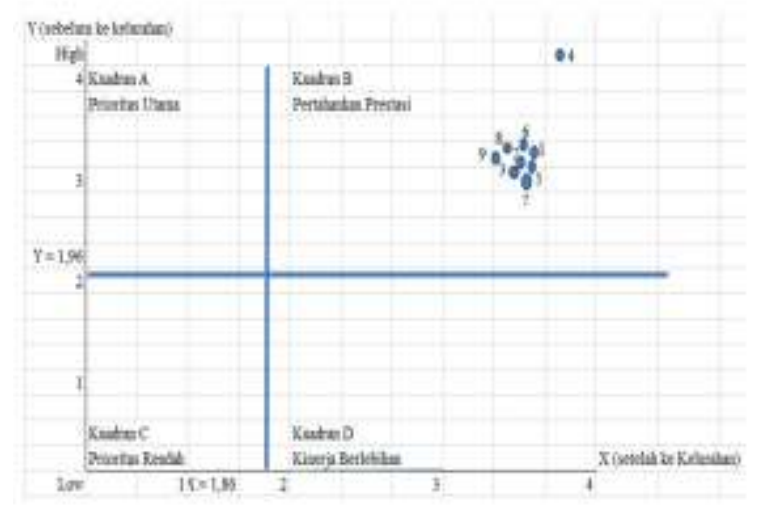

Sumber: Data Diolah

Gambar VII Diagram Kartesius Area Kelurahan di Jakarta Utara 
Dari perhitungan dan gambar VII yakni diagram kartisius didapat hasil yakni bahwa pelayanan yang diberikan berada pada Kuadran B ini menunjukan unsur atau jasa pokok pelayanan telah berhasil dilaksanakan. Pada gambar kartesius semua atribut berada di kuadran B yakni yang meliputi persyaratan, sistem, mekanisme dan prosedur, waktu penyelesaian, biaya/tarif, produk spesifikasi jenis pelayanan, kompetensi pelaksana, perilaku pelaksana, penanganan pengaduan, saran dan masukan, sarana dan prasarana puas dengan pelayanan publik era Anies Baswedan. Untuk itu wajib dipertahankan prestasi kinerja tersebut.

\section{Jakarta Selatan}

Di dalam kelurahan yang berada di area wilayah Jakarta Selatan di dapat hasil sebagai berikut :

Perhitungan Tingkat Kesesuaian Total Antara $\mathrm{X}$ (setelah) dengan Y (sebelum)

\begin{tabular}{|c|c|c|}
\hline \multirow{2}{*}{ TK total $=$} & $\Sigma \mathrm{X} 1$ & \multirow{2}{*}{ x $100 \%$} \\
\hline & $\Sigma Y 1$ & \\
\hline$\Sigma X 1$ & 4967 & \multirow{4}{*}{ x $100 \%$} \\
\hline$\Sigma Y 1$ & 4837 & \\
\hline \multirow[t]{2}{*}{ TK total $=$} & 4967 & \\
\hline & 4837 & \\
\hline
\end{tabular}

TK total $=\quad 103 \%$

Skor Rata-Rata Tingkat X dan Y

$\begin{array}{ccc}\text { Skor Rata-Rata } & =\frac{\mathrm{X} \text { rata-rata }}{\mathrm{k}} \\ \mathrm{X} & =\frac{30.29}{18} \\ \text { Titik Potong X } & =1.68 \\ \mathrm{Y} & =\frac{29.49}{18}\end{array}$

Titik Potong $\mathrm{Y}=1.64$

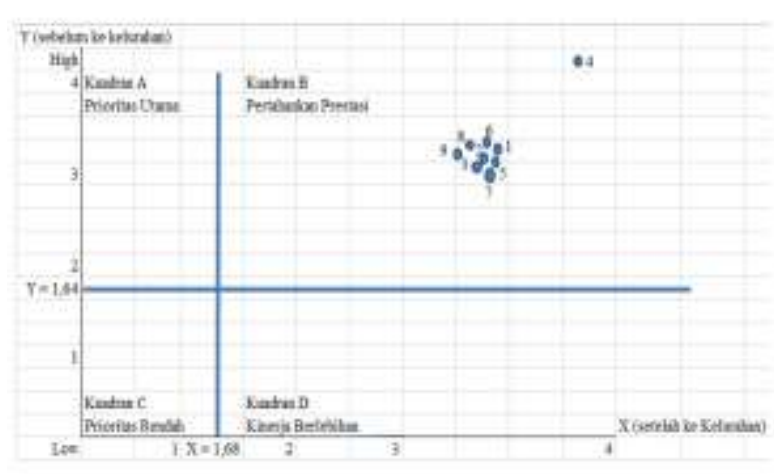

Sumber: Data Diolah

Gambar VIII Diagram Kartesius Area Kelurahan di Jakarta Selatan

Dari perhitungan dan gambar diagram kartesius didapat hasil yakni bahwa pelayanan yang diberikan berada pada Kuadran B ini menunjukan unsur atau jasa pokok pelayanan telah berhasil dilaksanakan. Pada gambar kartesius semua atribut berada di kuadran B yakni yang meliputi persyaratan, sistem, mekanisme dan prosedur, waktu penyelesaian, biaya/tarif, produk spesifikasi jenis pelayanan, kompetensi pelaksanaan, perilaku pelaksana, penanganan pengaduan, saran dan masukan, sarana dan prasarana puas dengan pelayanan publik era Anies Baswedan. Untuk itu wajib dipertahankan prestasi kinerja tersebut.

\section{Metode CSI}

Di dalam metode ini, peneliti menghadirkan dua jenis analisa data yang pertama secara keseluruhan wilayah dan yang kedua membaginya kedalam beberapa cluster area wilayah DKI Jakarta.

Secara garis besar, peneliti menemukan fakta empiris berkaitan dengan penggunaan metode CSI.

Untuk menginterpretasikan hasil dapat melihat Tabel IX Kriteria CSI dibawah ini.

Tabel 4 Kriteria CSI

\begin{tabular}{|c|c|c|}
\hline No & Nilai CSI (\%) & Keterangan CSI \\
\hline 1 & $81 \%-100 \%$ & Sangat Puas \\
\hline 2 & $66 \%-80,99 \%$ & Puas \\
\hline 3 & $51 \%-65,99 \%$ & Cukup Puas \\
\hline 4 & $35 \%-50,99 \%$ & Kurang Puas \\
\hline 5 & $0-34,99 \%$ & Tidak Puas \\
\hline
\end{tabular}

Sumber : (Widodo et al., 2018) 
Dari beberapa tahapan penentuan CSI maka dihasilkan data secara umum sebagai berikut

Tabel 5 Csi

Area Jakarta Pusat

\begin{tabular}{|c|c|c|c|c|c|c|c|}
\hline ITEM & MIS & WF & WS & WT & ITEM & MSS & $\mathrm{CSI}$ \\
\hline Y1 & 3.3 & 0,11 & 0,38 & \multirow{10}{*}{3,44} & $\mathrm{X} 1$ & 3,41 & \multirow{10}{*}{68,8} \\
\hline Y2 & 3.3 & 0,11 & 0,37 & & $\mathrm{X} 2$ & 3,38 & \\
\hline Y3 & 3.2 & 0,11 & 0,36 & & $\mathrm{X} 3$ & 3,33 & \\
\hline Y4 & 3.8 & 0,13 & 0,49 & & $\mathrm{X} 4$ & 3,85 & \\
\hline Y5 & 3.2 & 0,11 & 0,37 & & X5 & 3,41 & \\
\hline Y6 & 3.2 & 0,11 & 0,36 & & X6 & 3,31 & \\
\hline Y7 & 3.3 & 0,11 & 0,39 & & $\mathrm{X} 7$ & 3,46 & \\
\hline Y8 & 3.2 & 0,11 & 0,37 & & $\mathrm{X} 8$ & 3,40 & \\
\hline Y9 & 3.3 & 0,11 & 0,36 & & X9 & 3,33 & \\
\hline & 30,25 & & & & \multicolumn{2}{|c|}{30,90} & \\
\hline
\end{tabular}

Sumber: Data Diolah

Tabel 6 CSI

Area Jakarta Selatan

\begin{tabular}{|c|c|c|c|c|c|}
\hline Y8 & 3,97 & 0,11 & 0,45 & X8 & 3,98 \\
\hline Y9 & 3,85 & 0,11 & 0,36 & $\mathrm{x} 9$ & 3,29 \\
\hline & 35,27 & & & & 33,39 \\
\hline
\end{tabular}

Sumber: Data Diolah

Tabel 8 CSI

Area Jakarta Barat

\begin{tabular}{|c|c|c|c|c|c|c|c|}
\hline ITEM & MIS & WF & WS & WT & ITEM & MSS & CSI \\
\hline Y1 & 3,82 & 0,11 & 0,32 & \multirow{10}{*}{2,79} & $\mathrm{X} 1$ & 2,83 & \multirow{10}{*}{55,81} \\
\hline Y2 & 3,79 & 0,11 & 0,32 & & X2 & 2,89 & \\
\hline Y3 & 3,75 & 0,11 & 0,29 & & $\mathrm{X} 3$ & 2,61 & \\
\hline Y4 & 3,74 & 0,11 & 0,30 & & $\mathrm{X} 4$ & 2,73 & \\
\hline Y5 & 3,80 & 0,11 & 0,31 & & X5 & 2,78 & \\
\hline Y6 & 3,79 & 0,11 & 0,32 & & X6 & 2,87 & \\
\hline Y7 & 3,77 & 0,11 & 0,31 & & $\mathrm{X} 7$ & 2,79 & \\
\hline Y8 & 3,80 & 0,11 & 0,32 & & X8 & 2,90 & \\
\hline Y9 & 3,79 & 0,11 & 0,30 & & $\mathrm{X} 9$ & 2,71 & \\
\hline & 34,05 & & & & & 25,11 & \\
\hline
\end{tabular}

Sumber: Data Diolah

\begin{tabular}{|l|r|r|r|}
\hline \multicolumn{1}{|l|}{ ITEM } & \multicolumn{1}{|c|}{ MIS } & \multicolumn{1}{l|}{ WF } & \multicolumn{1}{l|}{ WS } \\
\hline Y1 & 3,30 & 0,11 & 0,38 \\
\hline Y2 & 3,28 & 0,11 & 0,37 \\
\hline Y3 & 3,20 & 0,11 & 0,35 \\
\hline Y4 & 3,44 & 0,12 & 0,43 \\
\hline Y5 & 3,22 & 0,11 & 0,36 \\
\hline Y6 & 3,29 & 0,11 & 0,37 \\
\hline Y7 & 3,26 & 0,11 & 0,37 \\
\hline Y8 & 3,26 & 0,11 & 0,37 \\
\hline Y9 & 3,24 & 0,11 & 0,37 \\
\hline & 29,49 & \\
\hline
\end{tabular}

Sumber: Data Diolah

Tabel 7. CSI

Area Jakarta Utara

\begin{tabular}{|c|c|c|c|c|c|c|c|}
\hline ITEM & MIS & WF & WS & WT & ITEM & MSS & $\mathrm{CSI}$ \\
\hline Y1 & 3,87 & 0,11 & 0,41 & \multirow{7}{*}{3,71} & $\mathrm{X} 1$ & 3,74 & \multirow{7}{*}{74,25} \\
\hline Y2 & 3,95 & 0,11 & 0,42 & & X2 & 3,77 & \\
\hline Y3 & 3,91 & 0,11 & 0,39 & & $\mathrm{X} 3$ & 3,49 & \\
\hline Y4 & 3,80 & 0,11 & 0,40 & & $\mathrm{X} 4$ & 3,69 & \\
\hline Y5 & 3,98 & 0,11 & 0,42 & & X5 & 3,77 & \\
\hline Y6 & 3,97 & 0,11 & 0,42 & & X6 & 3,76 & \\
\hline Y7 & 3,99 & 0,11 & 0,44 & & $\mathrm{X} 7$ & 3,93 & \\
\hline
\end{tabular}

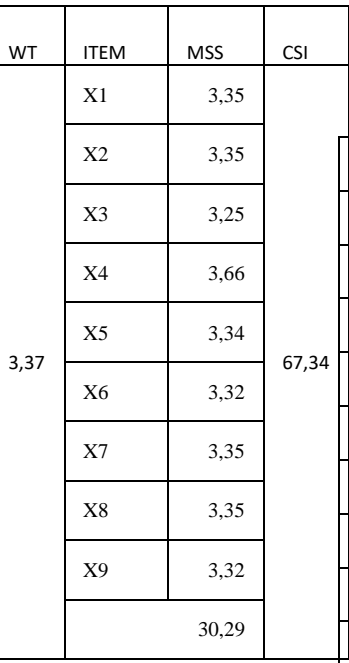

Tabel 9

Area Jakarta Timur

$\mid$\begin{tabular}{||l||}
\hline $\mathrm{Y}$ \\
\hline $\mathrm{Y} 2$ \\
\hline $\mathrm{Y}$ \\
\hline $\mathrm{Y} 4$ \\
\hline $\mathrm{Y} 5$ \\
\hline $\mathrm{Y} 6$ \\
\hline $\mathrm{Y}$ \\
\hline $\mathrm{Y}$ \\
\hline $\mathrm{Y}$ \\
\hline $\mathrm{Y}$
\end{tabular}

\begin{tabular}{|c|c|c|c|c|c|c|c|}
\hline ITEM & MIS & WF & ws & WT & ITEM & MSS & $\mathrm{CSI}$ \\
\hline Y1 & 3,81 & 0,11 & 0,38 & \multirow{9}{*}{3,24} & $\mathrm{X} 1$ & 3,33 & \multirow{10}{*}{64,7} \\
\hline Y2 & 3,77 & 0,11 & 0,37 & & $\mathrm{X} 2$ & 3,34 & \\
\hline Y3 & 3,72 & 0,11 & 0,30 & & X3 & 2,72 & \\
\hline Y4 & 3,82 & 0,11 & 0,45 & & $\mathrm{X} 4$ & 3,94 & \\
\hline Y5 & 3,68 & 0,11 & 0,35 & & X5 & 3,25 & \\
\hline Y6 & 3,71 & 0,11 & 0,37 & & x6 & 3,38 & \\
\hline Y7 & 3,78 & 0,11 & 0,34 & & $\mathrm{x} 7$ & 3,05 & \\
\hline Y8 & 3,67 & 0,11 & 0,33 & & $\mathrm{X} 8$ & 3,06 & \\
\hline Y9 & 3,74 & 0,11 & 0,33 & & $\mathrm{X} 9$ & 3,01 & \\
\hline & 33,71 & & & 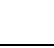 & & 29,10 & \\
\hline
\end{tabular}

Sumber: Data Diolah

Tabel X hingga tabel XIV tersebut dapat disimpulkan secara umum, pelayanan publik di kelurahan secara keseluruhan di wilayah DKI Jakarta selama era Anies Baswedan, warga merasa puas. Hal ini ditunjukan dengan capaian nilai CSI sebesar 66,35. Hal ini menunjukan bahwa pelayanan yang diberikan kepada warga sudah maksimal sehingga warga merasa puas terhadap pelayanan yang diberikan dengan kata lain 
persepsi warga terhadap pelayanan yang diberikan sesuai. Untuk menginterpretasikan hasil dapat melihat secara detail CSI per wilayah sehingga dapat menghasilkan temuan data empiris yang objektif. Berikut ini adalah hasil olahan data perhitungan CSI pelayanan publik di kelurahan yang berada di lima wilayah DKI Jakarta.

Dari tabel tersebut dapat diinterpretasikan hasil yakni hampir keseluruhan pelayanan publik di kelurahan di wilayah Provinsi DKI Jakarta memberikan kepuasan kepada warga sehingga persepsi warga terhadap pemerintahan Gubernur Anies Baswedan adalah baik. Dari data yang ada kita dapat melihat pelayanan di kelurahan yang berada di wilayah Jakarta Pusat, Jakarta Selatan dan Jakarta Utara memberikan pelayanan publik yang memuaskan warga. Hal ini terlihat dari nilai CSI ketiga wilayah tersebut yakni Jakarta Pusat dengan nilai CSI sebesar 68,81, Jakarta Selatan 67,34 serta Jakarta Utara sebesar 74,25. Dengan nilai tersebut mengindikasikan bahwa pelayanan yang diberikan kepada warga baik sehingga masyarakat di ketiga wilayah tersebut merasakan puas. Berbeda dengan dua wilayah Jakarta Barat dan Jakarta Timur yang memiliki nilai CSI sebesar 55, 81 serta 64,70. Dengan angka tersebut perlu adanya upaya peningkatan pelayanan publik di kelurahan untuk kedua wilayah tersebut.

\section{PENUTUP}

Dari uraian yang telah disampaikan, maka dapat disimpulkan bahwa persepsi warga DKI Jakarta terhadap pelayanan publik di kelurahan pada era Gubernur Anies Baswedan positif. Hal ini ditandai dengan nilai secara global baik CSI maupun IPA yang memberikan nilai positif yang dapat diintrepetasikan bahwa masyarakat DKI Jakarta pada umumnya merasa puas terhadap pelayanan yang diberikan kepada warga lewat pelayanan publik di dalam kelurahan. Hanya dua wilayah DKI Jakarta yang perlu untuk meningkatkan pelayanan agar warga DKI Jakarta dapat puas yakni kelurahan-kelurahan yang berada di wilayah Jakarta Barat dan Jakarta Timur.

Penelitian ini memerlukan juga perbaikan maka diharapkan untuk penelitian mendatang disarankan agar dapat meneliti lebih kompleks pengaruh kualitas layanan dan mencari hubungan antara persepsi serta kepuasan terhadap layanan yang ada.

\section{Ucapan terima kasih}

Ucapan Terima Kasih kami sampaikan kepada RISTEKDIKTI atas bantuan dana penelitian dan publikasi yang telah diberikan dalam bentuk PDP (Penelitian Dosen Pemula).

\section{REFERENSI}

Anggraini, L. D., Deoranto, P., \& Ikasari, D. M. (2015). Analisis Persepsi Konsumen Menggunakan Metode Importance Performance Analysis Dan Customer Satisfaction Index the Analysis of Consumer Perception Used Importance Performance Analysis Method and. Jurnal Industri, 4(2), 7481.

https://industria.ub.ac.id/index.php/ind ustri/article/view/179

Kemenpan. (2017). Peraturan Menteri Pendayagunaan Aparatur Negara Dan Reformasi Birokrasi Republik Indonesia Nomor 14 Tahun 2017 Tentang Pedoman Penyusunan Survei Kepuasan Masyarakat Unit Penyelenggara Pelayanan Publik. Pedoman Penyusunan Survei Kepuasan Masyarakat Unit Penyelenggara Pelayanan Publik, 708, 1-30. https://pemerintah.net/surveikepuasan-masyarakat-permenpan-14tahun-2017/

Kotler, P. (2012). Marketing management. Pearson Education Limited.

Kusumaningrum, A. E., \& Asfirotun, J. (2013). Analisis Kepuasan Pengguna Jasa Terhadap Kinerja Pt . Kereta Api Indonesia ( Persero ) ( Krl Commuter Line Jakarta Kota - Bogor ). Proceeding PESAT (Psikologi, Ekonomi, Sastra, Arsitektur \& Teknik Sipil), 5, 8-9. https://ejournal.gunadarma.ac.id/index. php/pesat/article/view/1224

Nalendra, A. R. A., Sariwaty, \& Suhaila, A. (2018). Pengaruh Implementasi Kebijakan Dan Budaya Organisasi Terhadap Kualitas Pelayanan Publik. Widya Cipta - Jurnal Sekretari Dan 
Manajemen, 2(1), 141-148. https://doi.org/10.31294/widyacipta.v2 i1.2444

Rindengan, M. (2016). Kepemimpinan Lurah Dalam Pelayanan Administrasi Di Kelurahan Tinoor I Kecamatan Tomohon Utara. Jurnal Politico, 3(1). https://ejournal.unsrat.ac.id/index.php/ politico/article/view/12126

Sastika, W. (2018). Analisis Kualitas Layanan dengan Menggunakan Eservice Quality untuk Mengetahui Kepuasan Pelanggan Belanja Online Shoppe (Studi Kasus: Pelanggan. Journals.Upi-Yai.Ac.Id, $\quad 2, \quad 6$. http://journals.upiyai.ac.id/index.php/ikraithhumaniora/article/download/127/56

Sugiyono. (2015). Metode Penelitian Kuantitatif Kualitatif dan $R \& D$ (Alfabeta (ed.)).

Widodo, S., Upgris, J. S.-J. I., \& 2018, U. (2018). Metode Customer Satisfaction Index (CSI) Untuk Mengetahui Pola Kepuasan Pelanggan Pada ECommerce Model Business to Customer. Journal.Upgris.Ac.Id. http://journal.upgris.ac.id/index.php/JI U/article/view/2224

\section{BIODATA PENULIS}

\section{Aloysius Rangga Aditya Nalendra}

Dosen pengajar aktif di universitas BSI.Peneliti pemula yang menggeluti dunia menulis aktif dalam komunitas dosen menulis ( Kode Pena) .

Bryan Givan, SE, MM, lahir di Jakarta saat ini aktif menjadi dosen tetap pada Universitas Bina Sarana Informatika Fakultas Ekonomi dan Bisnis. Selain mengajar pernah aktif menjabat sebagai koordinator unit prestasi kemahasiswaan, jabatan saat ini menjadi kepala kampus UBSI Jatiwaringin Jakarta. Karya ilmiah yang telah dihasilkan antara lain: Green Product dan Gaya Hidup Pengaruhnya terhadap Keputusan Pembelian, Determinan Loyalitas Pelanggan pada Operator Telepon Seluler, dll.
Imelda Sari, S.I.P., M.E., adalah alumni dari Universitas Indonesia, Depok tahun 2008, dari Program Studi Magister Perencanaan dan Kebijakan Publik. Saat ini aktif sebagai Dosen dan menjadi bagian di Unit Pengembang Akademik pada program studi Manajemen Fakultas Ekonomi dan Bisnis Universitas Bina Sarana Informatika. Aktif sebagai Asesor bidang Manajemen Bisnis dan kewirausahaan dan telah mengikuti tiga sertifikasi kompetensi BNSP yaitu Kewirausahaan Industri, Pelaksanaan Pemasaran dan Pendamping Kewirausahaan. Tercatat sebagai anggota Asosiasi Dosen Indonesia (ADI) dan anggota Ikatan Ilmuwan Indonesia Internasional (I-4). 